This document is confidential and is proprietary to the American Chemical Society and its authors. Do not copy or disclose without written permission. If you have received this item in error, notify the sender and delete all copies.

\title{
Cenosphere formation during single droplet combustion of heavy fuel oil
}

\begin{tabular}{|r|l|}
\hline Journal: & Energy \& Fuels \\
\hline Manuscript ID & ef-2018-03632m.R1 \\
\hline Manuscript Type: & Article \\
\hline Date Submitted by the & n/a \\
\hline Complete List of Authors: & $\begin{array}{l}\text { Jiang, Long; King Abdullah University of Science and Technology, Clean } \\
\text { Combustion Research Center } \\
\text { Elbaz, Ayman; King abdullha university of Science and Technology, Saudi } \\
\text { Arabia, Clean Combustion Research Center, CCRC } \\
\text { Guida, Paolo; King abdullha university of Science and Technology, Saudi } \\
\text { Arabia, Clean Combustion Research Center, CCRC } \\
\text { Al-Noman, Saeed; Saudi Electricity Company, Research and } \\
\text { Development department } \\
\text { Saxena, Saumitra; King abdullha university of Science and Technology, } \\
\text { Saudi Arabia, Clean Combustion Research Center, CCRC } \\
\text { Roberts, William; King Abdullah University of Science and Technology, } \\
\text { Clean Combustion Research Center }\end{array}$ \\
\hline
\end{tabular}

\section{SCHOLARONE" Manuscripts}




\section{Cenosphere formation during single droplet combustion of heavy fuel oil}

Long Jianga,c,* ${ }^{\mathrm{a},}$ Ayman M. Elbaz ${ }^{\mathrm{a}, \mathrm{d}}$, Paolo Guida ${ }^{\mathrm{a}}$, Saeed Mohammed Al-Noman ${ }^{\mathrm{b}}$, Saumitra Saxena ${ }^{\mathrm{a}}$, William L. Roberts $^{\mathrm{a}, *}$

a Clean Combustion Research Center, Physical Science and Engineering Division, King Abdullah University of Science and Technology (KAUST), Thuwal, Saudi Arabia

$b$ Research and Development department, Saudi Electricity Company, Saudi Arabia

c School of Energy and Power Engineering, Huazhong University of Science and Technology, Wuhan, China

d Faculty of Engineering Mataria, Helwan University, Cairo, Egypt

*Corresponding author:

Long Jiang,

E-mail: long.jiang@kaust.edu.sa; Tel: +966128084688; Address: Clean Combustion Research Center, King Abdullah University of Science and Technology (KAUST), Thuwal 23955-6900, Saudi Arabia

William L. Roberts,

E-mail: william.roberts@kaust.edu.sa; Tel: +966128084909; Address: Clean Combustion Research Center, King Abdullah University of Science and Technology (KAUST), Thuwal 23955-6900, Saudi Arabia

Abstracts: The current study aims to investigate cenosphere formation during single droplet combustion of heavy fuel oil (HFO). A droplet generator was developed to produce freely falling monodisperse droplets uniformly. With the aid of high-speed imaging, droplet diameter was verified to be well controlled within the range of 390 698 $\mu \mathrm{m}$, and droplets spacing distance was sufficient to avoid the droplet-droplet interactions. Impacts of operation conditions (initial HFO droplet size, temperature, and air co-flow rate) and asphaltene content on cenosphere formation in a drop tube furnace were then investigated. Three types of cenosphere morphology were observed by a field-emission scanning electron microscopy (SEM), namely larger hollow globules, medium porous cenospheres, and smaller cenospheres with a perfectly spherical and smooth structure. The SEM image results show the mean diameter of collected cenospheres increased as initial droplet size and asphaltene content increased, while it decreased as temperature and air co-flow rate increased. The energy dispersive X-ray spectra (EDX) results show these parameters also significantly influenced the evolution of cenosphere surface elemental composition. All parameters show linear effects on the surface content of $\mathrm{C}, \mathrm{O}$ and $\mathrm{S}$, excluding air co-flow rate. The increase of air co-flow temperature enhanced the droplet combustion, conversely, the larger the initial droplet size and asphaltene content inhibited droplet combustion. The non-linear effect of air co-flow rate indicates that it has an optimum rate for falling droplet combustion, as $90 \mathrm{slpm}$ based on the current experimental setup. Eventually, our study proposed the pathway of cenosphere formation during the HFO droplet combustion.

Keywords: Heavy fuel oil; Single droplet; Freely falling combustion; Cenosphere; Particulate material 


\section{Introduction}

Heavy fuel oil (HFO), as a byproduct from the crude oil refining process, is a cost-efficient and conventional fuel for industrial boilers, furnaces, and marine engines ${ }^{1-3}$. As one of the world's largest oil producer, Saudi Arabia has a considerable HFO output (26 Mt in $2016^{4}$ ), most of which is used for power generation, and besides, Saudi Arabia plans to newly increase a total capacity of HFO fired power plants by over 8 GW by $2019^{5}$, to switch away from direct burning of crude oil in the power sector. Although less attention has been paid to HFO combustion field due to development of the alternative fuels worldwide in recent years, there is an immediate need for enhanced research on HFO combustion as relevant to Saudi Arabia.

With the increasingly stringent environmental requirements worldwide, gas pollutant and particulate emissions from HFO combustion become a primary concern. As a result of the refining process, HFO consists of a considerable amount of pollutant elements (particularly sulfur) and macromolecule coke precursor hydrocarbons ${ }^{6,7}$. Thus, HFO combustion produces a large number of spheroidal particulates known as cenospheres resulting from incomplete combustion of the coke precursor compounds ${ }^{8}$, with diameters ranging from single digit to a few hundred microns. Cenosphere formation not only brings operational problems such as slagging, fouling and erosion to downstream devices, but also reduces the total combustion efficiency due to a considerable fraction of the unburned carbon contained in cenospheres. Furthermore, cenosphere emissions could result in air pollution that brings great harm to human respiratory health ${ }^{9,10}$. Thus, there are important implications to gain deep insight into the fundamental knowledge of cenosphere formation during HFO combustion.

Generally, HFO will be atomized as fine droplets for combustion, whereas it is too complicated to study the detailed process of cenosphere formation owing to a complex flow field and considerable interactions between plenty of droplets in spray combustion. Accordingly, combustion of the single droplet, either freely falling ${ }^{11-16}$ or suspended on a filament ${ }^{16-21}$ with controlled diameter have been exploited to reveal droplet burning behaviors and fundamental processes of cenosphere formation. Bomo et al. ${ }^{13}$ studied cenosphere formation during pyrolysis of HFO droplet, and their results showed cenospheres were formed at much lower temperature than soot. Cenosphere was yielded from each single droplet, rather than from carbonization of fuel at the gas/liquid interface, and it was more dependent on the chemical structure of asphaltene than on its amount. Clayton and Back 22 characterized physicochemical properties of cenospheres produced from an HFO fired power plant, and found typical large and small spheroidal, porous and hollow cenospheres with the diameter of $100-200 \mu \mathrm{m}$ and $20-40 \mu \mathrm{m}$, respectively. They also found a 
relatively rich percentage content of $\mathrm{V}, \mathrm{S}, \mathrm{Fe}$ and $\mathrm{Na}$ in cenospheres which was a potential reason for high-temperature corrosion from their deposition on heat exchanger surfaces. Allouis et al. ${ }^{23}$ presented similar results upon shape and surface elemental composition of particles emitted from HFO combustion. Bartle et al. ${ }^{7}$ studied combustion of both suspended and freely falling HFO droplets with different asphaltene contents, and found that asphaltene presented in HFO was a major factor in the formation of emitted smoke including cenospheres. They also stated that asphaltene reduced ignition delay times, but did not influence the burning time of droplets. It is also well established that cenosphere formation is the net result of two processes: liquid-phase thermal cracking to form a shell and subsequent oxidation of the shell to form a hollow cenosphere 11, 22, 24. The initial shell formation is strongly dependent on fuel properties while it is mainly independent on burning conditions. On the other side, the latter shell oxidation is largely dependent on the burning conditions while its burning behavior is mainly determined by the initial shell formation process which controls the mass and morphology of the shell ${ }^{11}$. Although, these previous studies on droplet combustion have obtained valuable information, there remains questions on composition evolution and formation of cenosphere under a wide range of reaction parameters. Such information is very important to unravel the particulate matter formation mechanism or mechanisms during HFO combustion. However, to the authors' best knowledge, few studies focuses on the influence of a wide range of reaction parameters including droplet thermal path parameters (air co-flow rate and ambient temperature) and droplet properties (initial droplet size and droplet asphaltene contents) on cenosphere formation and composition evolution during HFO freely falling droplet combustion. Recently, the effect of the asphaltene content on the combustion of the HFO droplet ${ }^{21}$ was investigated, however this work does not show the effect of the initial boundary condition and the effect of the thermal on the cenosphere formation.

In the current study, a droplet generator was developed to produce monodisperse $\mathrm{HFO}$ droplets. A high-speed camera imaging was used to determine the size and space of falling droplets. Combustion of freely falling monodisperse droplets without the interference of droplet-droplet interactions was implemented in a drop tube furnace. The impacts of temperature, initial droplet size, air co-flow rate and asphaltene content on morphology, size and surface elemental composition of produced cenospheres was studied by using the field-emission scanning electron microscopyenergy dispersive X-ray spectra (SEM-EDX). Eventually, the pathway of different types of cenosphere formation was proposed based on behaviors of single suspended HFO droplet combustion. 


\section{Experimental}

\subsection{Materials}

The HFO sample was collected from the Shoaiba power plant in Saudi Arabia. Elemental composition and physical properties of the HFO were determined by using a series of standard tests, and the results are listed in Table 1.

Table 1 The elemental composition and physical properties of HFO

\begin{tabular}{lccc}
\hline & Result & LOD $^{\text {a }}$ & Test standard \\
\hline Elemental composition (wt. \%) & & & \\
Carbon & 85.1 & 0.1 & EPA 440.0 \\
Hydrogen & 10.7 & 0.1 & EPA 440.0 \\
Nitrogen & 0.4 & 0.1 & EPA 440.0 \\
Oxygen & $<5.0$ & 5.0 & EPA 440.0 \\
Sulfur & 3.7 & 0.1 & ASTM D4294-10 \\
& & & \\
Physical properties & & & \\
Density at 20 ${ }^{\circ} \mathrm{C}(\mathrm{kg} / \mathrm{m} 3)$ & 966.8 & - & ASTM D4052-11 \\
Kinematic viscosity at $40{ }^{\circ} \mathrm{C}(\mathrm{cSt})$ & 617.7 & - & ASTM D445-12 \\
Asphaltenes content & $8.2 \%$ & - & IP 143 \\
Ash content (wt. \%) & $<0.1$ & 0.1 & ASTM D482 \\
Higher heating values (MJ/Kg) & 43.4 & 0.5 & ASTM D4868 \\
Lower heating values $(\mathrm{MJ} / \mathrm{Kg})$ & 41.1 & 0.5 & ASTM D4868 \\
& & & \\
Metals (mg/kg) & & & IP 501-05 \\
Nickel & 22.2 & 0.5 & IP 501-05M \\
Potassium & 10.7 & 5.0 & IP 501-05 501-05 \\
Sodium & 17.3 & 2.0 & IP 501-05 \\
Vanadium & 43.3 & 0.2 & \\
Zinc & $<0.5$ & 0.5 & \\
\hline
\end{tabular}

a: limit of detection

2.2 Initial droplet size calculation

A capillary droplet generator, which has been developed from the design of Green et al. ${ }^{25}$ that was applied to high viscosity slurries, was used to produce monodisperse falling droplets of HFO in this study. It consists of a hollow main body, a capillary tube through which the HFO was fed, a fine inducing wire (the diameter of 75 100 $\mu \mathrm{m}$ ) assembled at the tip of the capillary tube, and a carrier gas inlet connected to the hollow chamber of the generator as presented in Figure 1. The capillary tube penetrates through the main body. Droplet diameter and spacing distance can be controlled by varying the capillary tube size, the HFO feeding rate, and the carrier gas flow rate. In this study, the inner diameter of the capillary tube was selected as $350 \mu \mathrm{m}$. The HFO was heated at $130{ }^{\circ} \mathrm{C}$, and its feeding rate was 30 60 $\mu \mathrm{l} / \mathrm{min}$ controlled by a high-pressure syringe pump (NE 8000 New Era Pump System). A mass flowmeter controlled the air carrier gas flow rate varying between 
2 and 3.5 slpm (standard liter per minute).

The initial HFO droplet size and spacing distance produced from the capillary droplet generator were determined by using a high-speed camera system as shown in Figure 1. The work principle of this droplet generator is similar to the film-based holography technique such that the diffusive sheet was illuminated by a cooperated light source, and the interference between the scattered light waves from the HFO droplet and the illuminated sheet was projected onto the charge coupled device (CCD) sensor of the camera. The high-speed camera then recorded a sequence of freely falling droplets. The camera frame rate and exposure time are $11 \mathrm{KHz}$ and $100 \mu \mathrm{s}$, respectively.

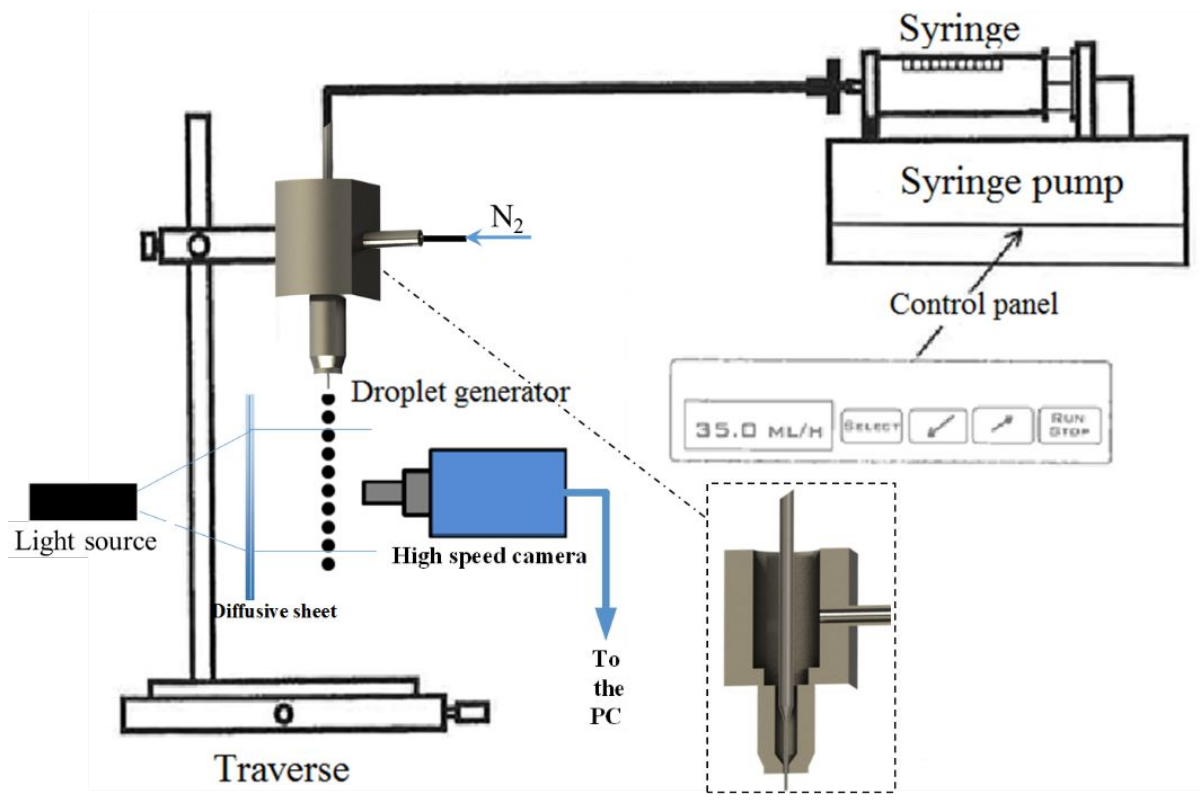

Figure 1 The high-speed camera system for calculation of initial HFO droplet size and spacing

One case is presented in Figure 2 to elaborate the calculation procedure of initial HFO droplet size and spacing. The scale of calibration ruler is $0.5 \mathrm{~mm}$. The diameter of sequent freely falling droplets can be directly calculated by the calibration ruler. The droplet spacing distance can be calculated by the following equation:

$D=V_{\text {droplet }} \times t=V_{\text {droplet }} \times n \times \frac{1}{R_{f}}$

where $D$ represents the distance between two sequent droplets; $t$ represents the recorded interval time between two sequent droplets; $n$ represents numbers of the blank frames between two sequent droplets; $R_{f}$ represents the frame rate of the high-speed camera $(11 \mathrm{KHz}) ; V_{\text {droplet }}$ means the droplet falling speed, which can be approximately calculated by the following equation:

$V_{\text {droplet }}=\frac{H}{t_{1}}=\frac{H}{n_{1} \times \frac{1}{R_{f}}}$

where $H$ means the corresponding height of the frame that can be calculated by the calibration ruler; $t_{1}$ means the time that the droplet passes through the recording area; $n_{1}$ represents numbers of the frames that the droplet passes through. Similarly, the spacing multiples of the diameter can be calculated by the distance divided by the droplet diameter. 


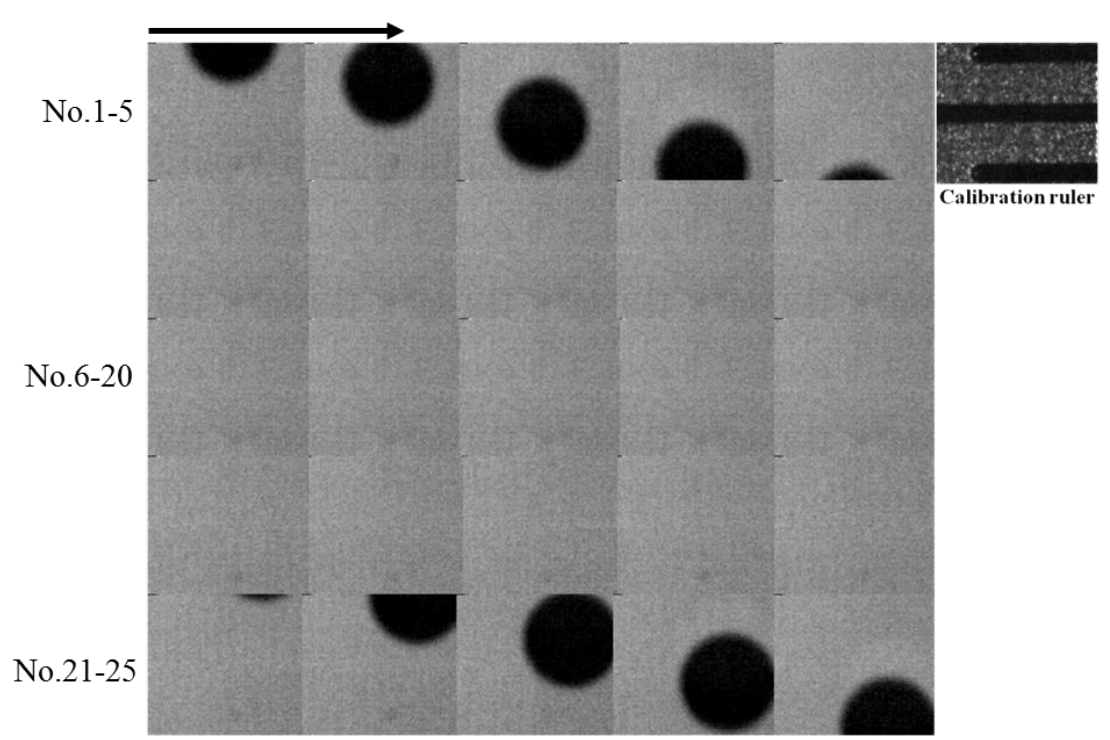

Figure 2 One case of the recorded two sequent single falling droplets (carrier gas flow rate of 2.5 slpm and HFO flow rate of $50 \mu \mathrm{L} / \mathrm{min})$

2.3 Experiment setup and procedure of falling droplet combustion

Freely falling droplet combustion of HFO was conducted in a laboratory-scale drop tube furnace, schematized in Figure 3. It consists mainly of three parts: (1) a monodisperse droplet generation system, which has been characterized in Section 2.2; (2) a combustion system, which is composed of a three-stage temperature-controlled furnace and a quartz reactor (inner diameter: 134 mm; height: $1500 \mathrm{~mm}$ ); (3) a quartz sampler, which is cooled by chilled water, and a glass fiber filter is placed at the bottom of the sampler to collect the produced cenospheres.

The quartz reactor was heated to the desired temperatures, and simultaneously the co-flow air was fed through four holes which were symmetrically distributed surrounding the central droplet entrance hole. The co-flow air was preheated at a setting temperature of $600^{\circ} \mathrm{C}$ by an in-line heater (Sylvania heater, F074719, 8000 Watts). A mass flowmeter controlled its flow rate. A ceramic honeycomb was fixed near the air nozzle to uniform the air flow field. When the temperature stabilized, the droplet generator was switched on, and the generated droplets freely fell into the furnace to be burned. The flue gas was cooled by the quartz sampler, and then the cenospheres produced from droplet combustion were collected by the filter. The exhaust was then sucked to the fume hood by a blower. Eventually, the collected cenospheres were analyzed by an SEM-EDX method (FEI Quanta 600, USA equipped with EDAX APOLLO XL, USA) to understand the impacts of operating conditions and asphaltene content on cenosphere formation. 
Table 2 The summarized experimental conditions

\begin{tabular}{ccccc}
\hline No. & $\begin{array}{c}\text { Initial droplet size } \\
(\mu \mathrm{m})\end{array}$ & $\begin{array}{c}\text { Temperature } \\
\left({ }^{\circ} \mathrm{C}\right)\end{array}$ & $\begin{array}{c}\text { Air co-flow rate } \\
(\text { slpm })\end{array}$ & $\begin{array}{c}\text { Asphaltene } \\
\text { content }(\mathrm{wt} \%)\end{array}$ \\
\hline$\# 1$ & $698 \pm 77 ; 510 \pm 42 ; 460 \pm 40 ; 390 \pm 69$ & 800 & 90 & 8 \\
$\# 2$ & $460 \pm 40$ & $700 ; 800 ; 900$ & 90 & 8 \\
$\# 3$ & $460 \pm 40$ & 800 & $30 ; 50 ; 90 ;$ & 8 \\
$\# 4$ & $460 \pm 40$ & 800 & $110 ; 130 ; 150$ & $8 ; 12 ; 16$ \\
\hline
\end{tabular}


2.4 Experiment setup and procedure of single droplet combustion

To unravel the pathway of cenosphere formation during the HFO droplet combustion, suspended droplet combustion was also implemented as shown in Figure 4.

The convective air stream, which was also preheated at a setting temperature of $600{ }^{\circ} \mathrm{C}$ by the inline heater (Sylvania heater, F074719, 8000 Watts), flowed vertically upward through a ceramic honeycomb located at the bottom of a quartz tube (inner diameter: $134 \mathrm{~mm}$; height: $750 \mathrm{~mm}$ ). The tube was electrically heated at a temperature of $750{ }^{\circ} \mathrm{C}$ to get the desired temperature air flow to ignite HFO droplet. The air flow rate was kept at $20 \mathrm{slpm}$ (the corresponding air rate is $0.082 \mathrm{~m} / \mathrm{s}$ based on the mass flux). When the air flow temperature was stable, an HFO droplet was suspended on the conjunction point of an Omega type $S$ thermocouple with a diameter of $75 \mu \mathrm{m}$ and inserted quickly into the centreline of the quartz tube to be ignited. The air-cooled jacket surrounded suspended droplet was used to prevent preheat and volatilization of the HFO droplet during its insertion. The ignition behaviors of HFO droplet was then recorded by the similar high-speed camera imaging system mentioned in Section 2.2. The recorded frame rate is 200 frames/s. The temperature profile of HFO droplet can be measured by the Omega thermocouple.

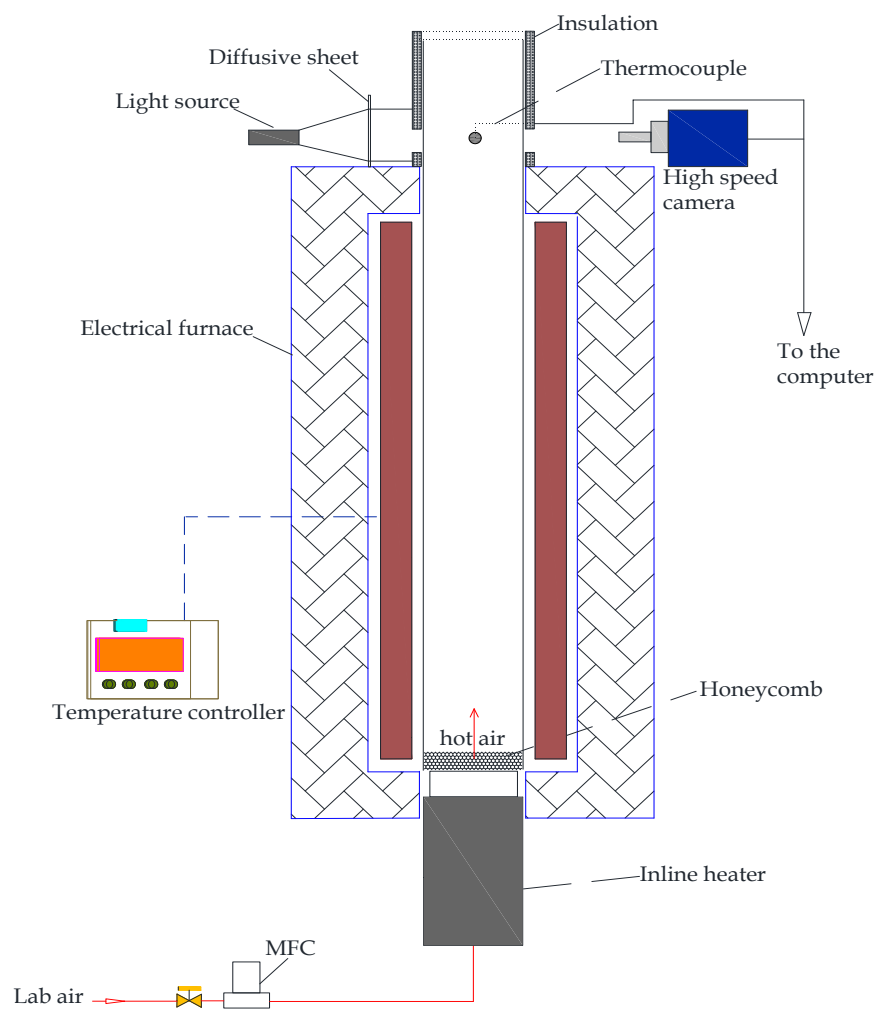

Figure 4 Schematic of the single suspended droplet combustion setup

\section{Results and discussion}

\subsection{Initial droplet size and spacing}

Figure 5(a) shows the initial droplet size distribution at different flow rates of HFO and carrier gas. The droplet diameter ranged from 390 to $698 \mu \mathrm{m}$, and it decreased with an increase in the carrier 
gas flow rate. Figure 5(b) shows the droplet space distribution under different droplet generation conditions. The droplet spacing distance decreased with an increase of the flow rate of both HFO and carrier gas. The published literature stated that the droplets that were spaced at least 30 diameters ${ }^{22}$, even 60 diameters ${ }^{11}$ apart could ensure their independent burning in the absence of interferences from the droplet-droplet interaction. As shown in Figure 5(b), the current droplet spacing ranged from 190 to 800 times of the initial droplet diameter, which appears sufficient to avoid the droplet-droplet interaction interference.

Figure 5 shows that the capillary droplet generator can well control the size and spacing of the HFO droplet. Thus, the HFO flow rate of $50 \mu \mathrm{L} /$ min was further selected for the generator. In the current study, the droplets with different initial diameters were generated by varying the carrier gas flow rate, namely $698 \pm 77 ; 510 \pm 42 ; 460 \pm 40 ; 390 \pm 69$ microns, to explore the effect of initial droplet diameters on the cenosphere formation.

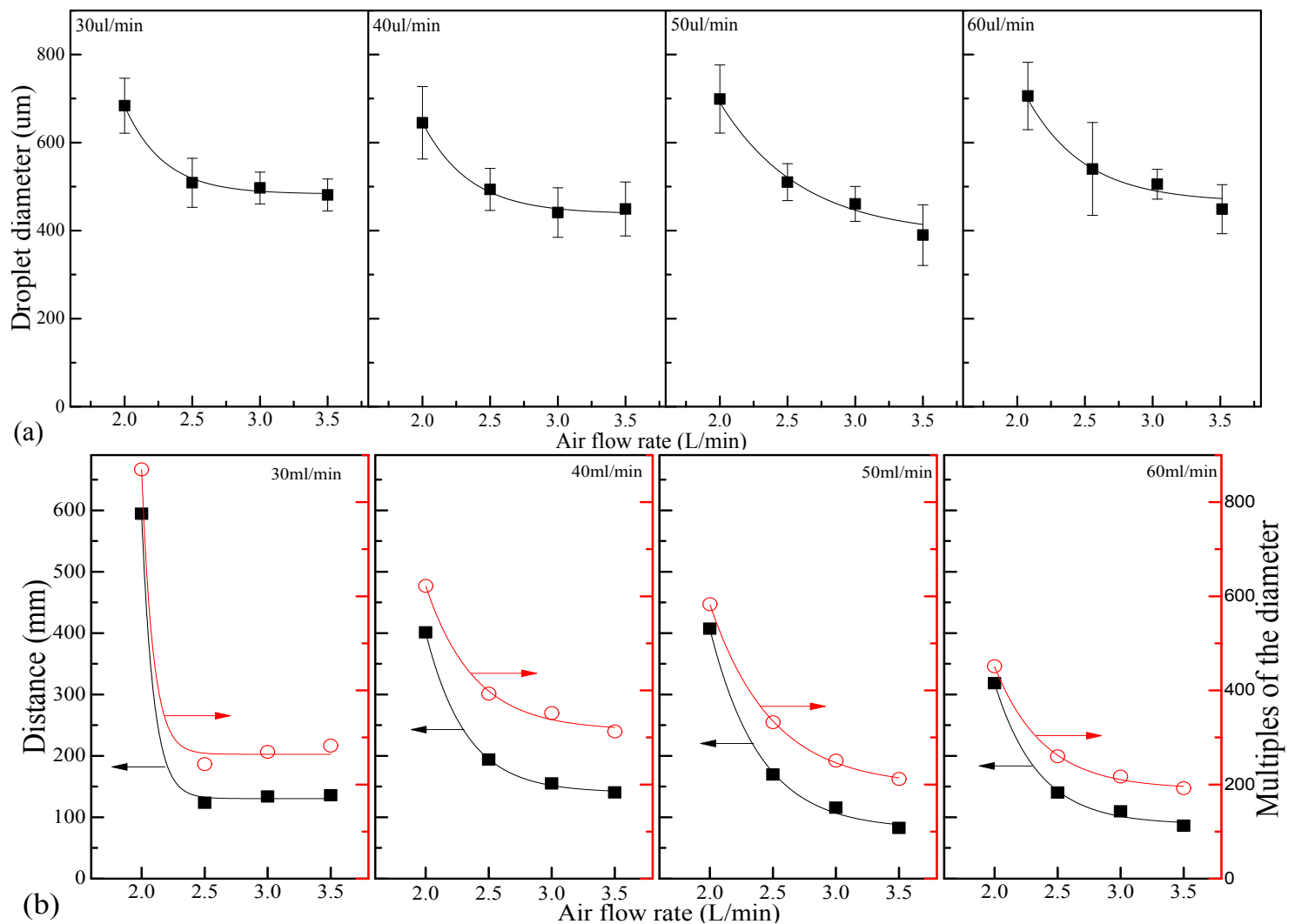

Figure 5 HFO droplet size and space distribution. (a) initial droplet size; (b) droplet space distribution 3.2 Cenosphere morphology

Three types of morphology were found in the collected cenospheres under different combustion conditions from SEM figures. Figure 6 presents one case under Condition \#1 listed in Table 2 with the initial HFO droplet diameter of $460 \pm 40 \mu \mathrm{m}$.

Type $\mathrm{A}$ is a common morphology that has been widely observed $22,26-30$, and it has a carbonaceous and porous shell. Its size is smaller than the initial HFO droplet size.

The second type (Type B) is mentioned as globules in the work of Kwack et al. ${ }^{27}$ whose diameter 
can even reach larger than that of initial droplet diameter. It is hollow inside and contains a skeleton and some bubbles. However, the globules show no blowholes at the surface as seen on the type A cenosphere. This structure is also observed by Moszkowicz et al. ${ }^{31}$ during fast pyrolysis of heavy fuel oil droplets, by Gay et al. ${ }^{28}$ during bituminous coals in a fluidized bed and by Wornat et al. ${ }^{12}$ from single droplet combustion of pine oil.

The last type (Type C) has perfectly spherical and smooth morphology, whose diameter is much smaller than other two types of cenosphere, ranging from 10 to 100 microns. It is also hollow but does not present any porous structure on the surface. One interesting phenomenon should be mentioned here that most of the published studies ${ }^{12,22,26-31}$ on cenosphere formation only observed one or two types of morphology including larger hollow globules and medium porous cenospheres. But in our current work, we observed three types of cenosphere morphology under combustion conditions without the interference of droplet-droplet interactions, including not only above two types but also this very fine type with a perfectly spherical and smooth structure.

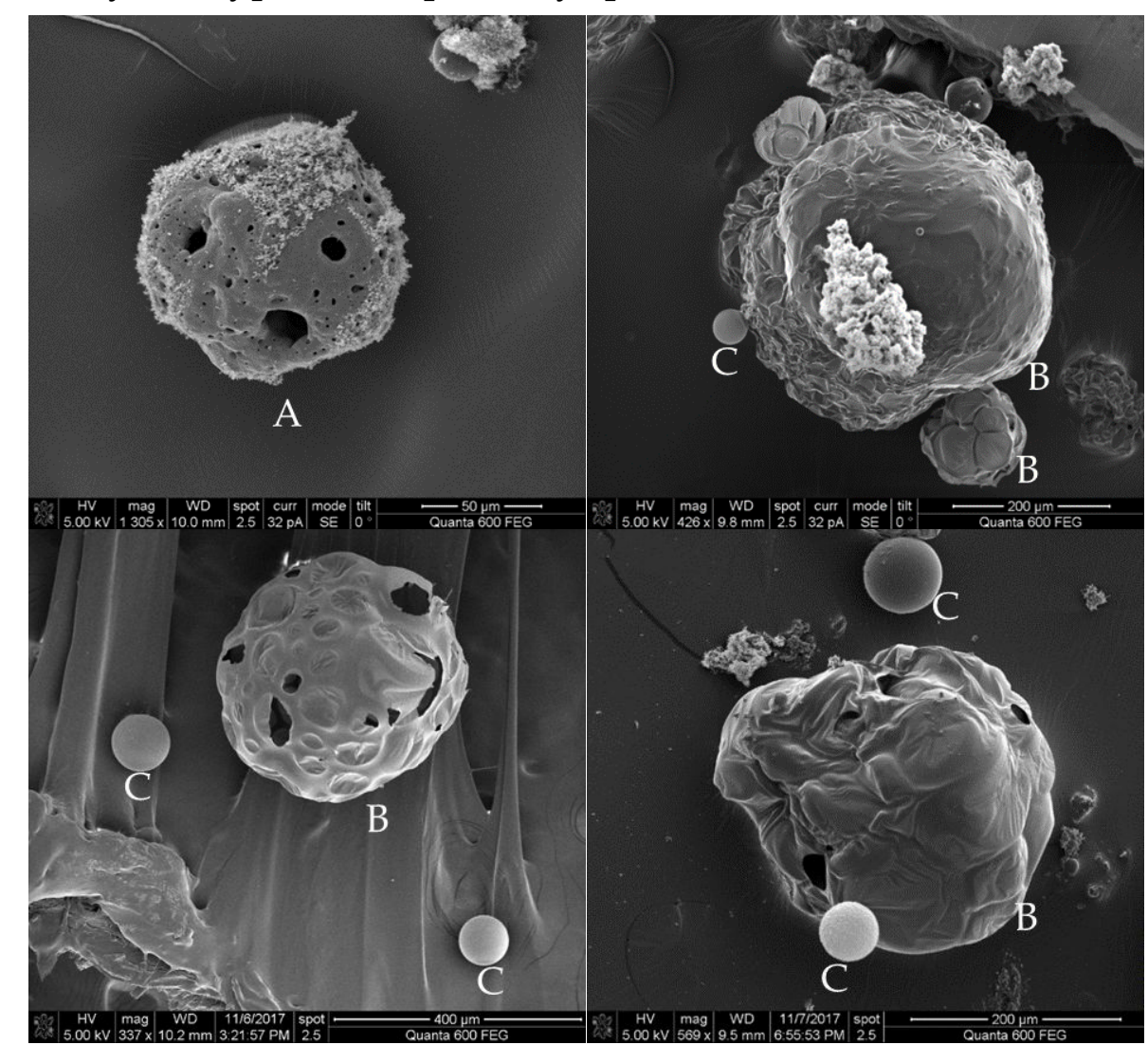

Figure 6 Three types of cenospheres collected from HFO droplet combustion

3.3 Effect of operating conditions and asphaltene content on cenosphere size

Figure 7 shows the effect of initial droplet size, temperature, air co-flow rate and asphaltene content on the mean diameter of cenospheres (corresponding to Condition \#1-4 listed in Table 2, respectively). The mean diameter of cenospheres was statistically calculated from all cenospheres observed in SEM figures.

Figure 7(a) shows the mean diameter of cenospheres was between 225 and $300 \mu \mathrm{m}$, nearly half ACS Paragon Plus Environment 
of their initial droplet. Unsurprisingly, the mean diameter of cenospheres increased as the initial droplet size increases. Figure $7(b-d)$ shows that the mean diameter of cenospheres decreased as temperature and air co-flow rate increased, while it increased as asphaltene content increased. The further detailed explanation for the effects of these parameters on cenosphere size will be presented in the following Section 3.6.
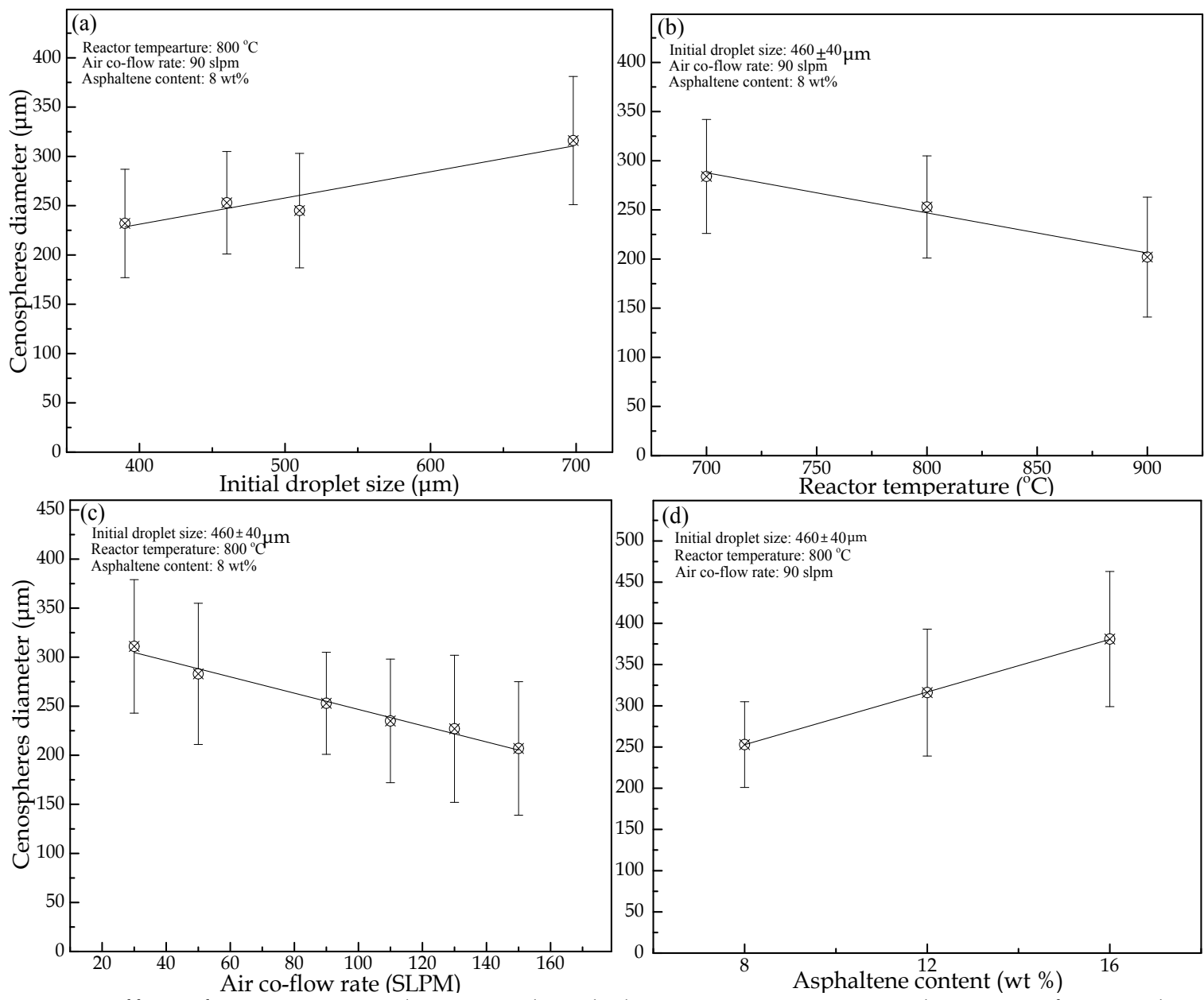

Figure 7 Effect of operating conditions and asphaltene content on mean diameter of cenospheres

3.4 Effect of operating conditions and asphaltene content on surface elemental composition

Figure 8 shows the effect of the operating conditions and asphaltene content on the surface elemental composition of cenosphere. The experimental conditions were the same as listed in Table 2. It should be noted here that only main elements of $\mathrm{C}, \mathrm{O}$ and $\mathrm{S}$ are presented, whose contents range from 80 to $85 \mathrm{wt} \%, 5$ to $13 \mathrm{wt} \%$, and 4 to $8 \mathrm{wt} \%$, respectively. The concentrations of the trace metals such as $\mathrm{V}, \mathrm{Ti}$, and $\mathrm{Ni}$ are very low that exceeds the limit of detection of EDX and they are not present here.

Evolution of $\mathrm{C}$ and $\mathrm{O}$ contents at the surface is an indicator of droplet combustion status. When the droplet combustion is enhanced, it means that the oxidation reactions with carbon at the surface of cenosphere are intensified. This intensified oxidation reactions could form more oxygen functional groups and oxides at the surface, leading to an increase in O content and a decrease in C content. 
As shown in Figure 8(a), C content increased while $\mathrm{O}$ and $\mathrm{S}$ content decreased with an increase of the initial droplet size of HFO. This means that increasing initial droplet size of HFO could cause worse incomplete combustion, leading to lower degree of oxidation reactions and higher C content on the surface of cenosphere. Due to lower oxidation reactions, the formation of oxygen functional groups and oxides on cenosphere would be inhibited, resulting in $\mathrm{O}$ content decreasing on the surface. In other words, finer atomization of the HFO droplets was in favor of their complete combustion. A slight decrease of $S$ content on cenosphere was due to the obvious increase of $C$ content.

Figure 8(b) shows that the increasing temperature promoted droplet combustion and enhanced oxidation reactions, leading to $\mathrm{C}$ content decreasing and $\mathrm{O}$ content increasing on cenosphere. The increasing temperature could also enhance sulfur oxidations to form more gaseous $\mathrm{SO}_{\mathrm{x}}$ products, causing a decrease of $S$ content on cenosphere.

As shown in Figure 8(c), the parameter of air co-flow rate affecting surface elemental composition does not present a linear relation. With air co-flow rate increasing, $\mathrm{C}$ content first decreased and then increased, while $\mathrm{O}$ content has a reverse trend. The effect of air co-flow rate on $S$ content was insignificant. An in-line heater heated the co-flow air, and the increasing air co-flow rate would bring more heat into the entrance area of the reactor, enhancing droplet combustion. On the other hand, the increasing air co-flow rate would cause a shorter combustion residence time of droplet, worsening the incomplete combustion of the droplet. Thus, the interaction effect of these two factors led to the first rise and afterward fall of C content. It can be concluded that the co-flow air has an optimum rate for falling droplet combustion, as $90 \mathrm{slpm}$ based on the current experimental conditions.

Figure 8(d) shows that asphaltene content also played a significant role in the surface elemental composition of cenosphere. Asphaltene is well known as the most complex and heaviest fraction of crude oil 32,33 . Its combustion reactivity is also much lower than lighter fractions. Thus, the increasing asphaltene content would also worsen incomplete combustion of HFO droplet, resulting in $\mathrm{C}$ content increasing and $\mathrm{O}$ content decreasing. Also, as well studied by Ancheyta ${ }^{32}$ and Riazi ${ }^{34}$, S content is very closely related to heavy fractions (with low American Petroleum Institute (API) or high specific gravity) in petroleum mixtures, and most of $S$ species are in asphaltene and other very heavy aromatics. Accordingly, the increasing asphaltene content could increase S content in HFO, and $\mathrm{S}$ content on cenosphere would increase. 

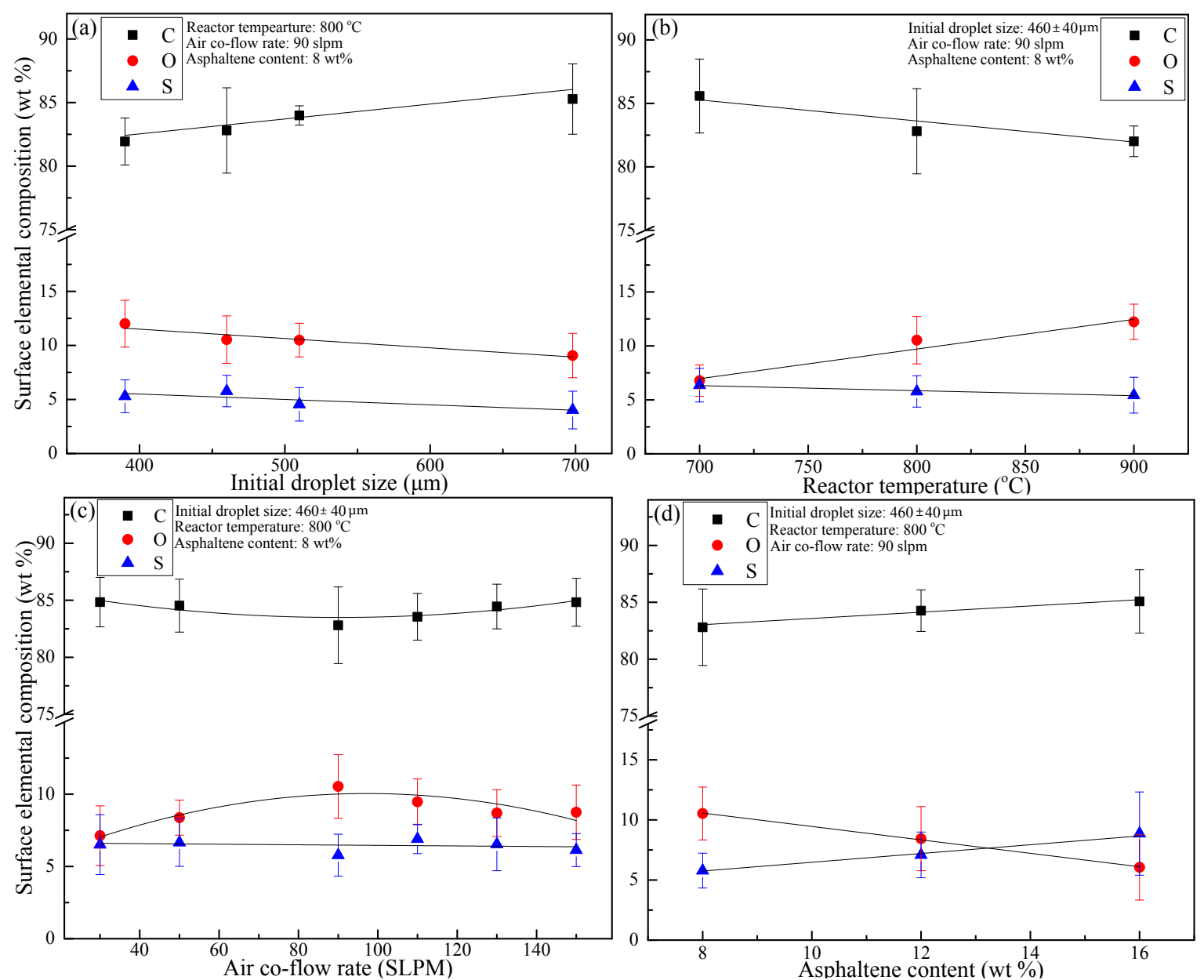

Figure 8 Effect of operating conditions and asphaltene content on the surface elemental composition of cenospheres

\subsection{Single suspended droplet combustion behaviors}

Figure 9 and 10 show the suspended HFO droplet size and temperature evolution with and without ignition, respectively in the furnace. The transient high-speed images of HFO droplet were obtained from the corresponding high-speed camera videos (as shown in Supplementary data of Video 1 and 2 , separately).

As shown in Figure 9 and Supplementary 1, the droplet with ignition would undergo five stages. (1) Boiling and vaporization of lighter components starting at a temperature of $110^{\circ} \mathrm{C}$ due to heat transfer from ambient to the droplet. In this stage, the droplet was slightly swollen due to continuous gaseous diffusion and vaporization, which causes an increase of droplet size and forms the first peak as shown in Figure 9 (b). (2) Devolatilization and cracking of heavier components starting at a temperature of $300^{\circ} \mathrm{C}$ due to heat transfer from the surface to the interior of the droplet. Meanwhile, some small fractions significantly splashed out from the droplet as shown in the transient images (Figure 9 (a)). These both caused a successive decrease of droplet size in this stage. (3) Formation of a viscous shell and volatile accumulation inside the shell between the temperature of $300 \sim 530{ }^{\circ} \mathrm{C}$. With volatile diffusion and vaporization, the internal heavier components such as asphaltene in the droplet moved towards the surface and accumulated at the surface, forming a 
viscous shell. This viscous shell could prevent the escape of volatile components. Then the droplet was swollen again, which causes another increase of droplet size and forms the second peak as shown in Figure 9 (b). (4) Penetration and ignition of accumulated volatiles starting at a temperature of $530{ }^{\circ} \mathrm{C}$. The inside accumulated volatiles eventually penetrated through some weak locations of the shell, which causes the second decrease of the droplet size. If the amount of the penetrated volatiles were sufficient within the flammability range, it would be ignited by the surrounding hot air flow. The ignition caused a sharp rise in temperature, which greatly intensified the volatilization of other components. This intensifying volatilization led to a further remarkable and fast swell of droplet resulting in the most obvious peak of droplet size as shown in Figure 9 (b). As a result of intensifying volatilization, the flame was also intensified until depletion of any volatile components. (5) Shell shrink and solid residue combustion starting at a temperature of $698^{\circ} \mathrm{C}$. After the depletion of any volatile components, the surface tension caused a fast shrink of the shell. The resulting solid residue burned subsequently until quenching. The size of the final solid residue is much smaller than its initial droplet size. Thus, this solid residue can be concluded to form the type A cenosphere.

As shown in Figure 10 and Supplementary 2, compared to the condition with the ignition, the droplet without ignition would undergo only four stages, excluding ignition and solid residue burning stages. The droplet size changing in the initial period is similar to the former condition. However, if the amount of released volatiles was not within the flammability range, and the droplet was not ignited. Due to the absence of the ignition stage, the temperature rise and the heat transfer were much slower, leading to the stable and longtime swelling of the viscous shell. The slower heat transfer can also be verified by the peak corresponding time of around $6.8 \mathrm{~s}$ as presented in Figure 10 (b) which is around $1.7 \mathrm{~s}$ later than that presented in Figure 9 (b). Thus, the droplet size changing in the last stage was much different. Though the ignition did not occur, additional volatile components could also vaporize and accumulate due to an increase of the droplet interior temperature caused by heat transfer from the surrounding atmosphere. But due to much slower droplet interior temperature rise, the droplet swelling was much mild. The maximum droplet size in this condition was larger than in the former condition. Eventually, the accumulated volatiles would also slowly penetrate through some weak locations of the shell at a temperature of $600{ }^{\circ} \mathrm{C}$ based on the results of Figure 10 (c), and its weaker surface tension caused a low-intensity shell shrink. The final solid residue size here is larger than its initial droplet size and is also much larger than the final residue size in the former condition. Thus, this solid residue here can be concluded to form the type B (globule) cenosphere.

Furthermore, the small fractions splashing out from the droplet can be observed in both Figure ACS Paragon Plus Environment 
9(a) and Figure 10 (a). These small splashing fractions can be concluded to form the small type C cenosphere with a perfectly spherical and smooth structure.

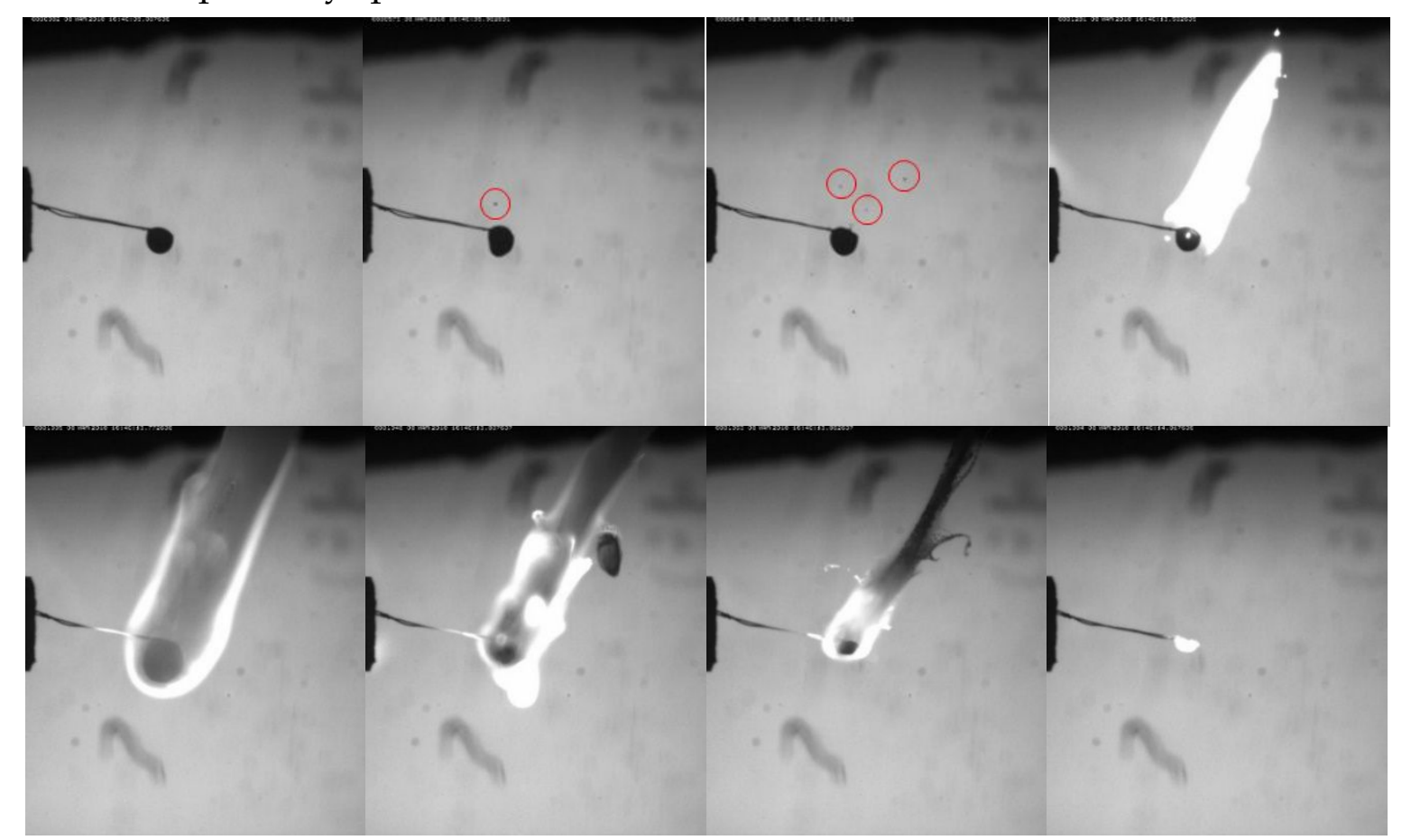

(a)
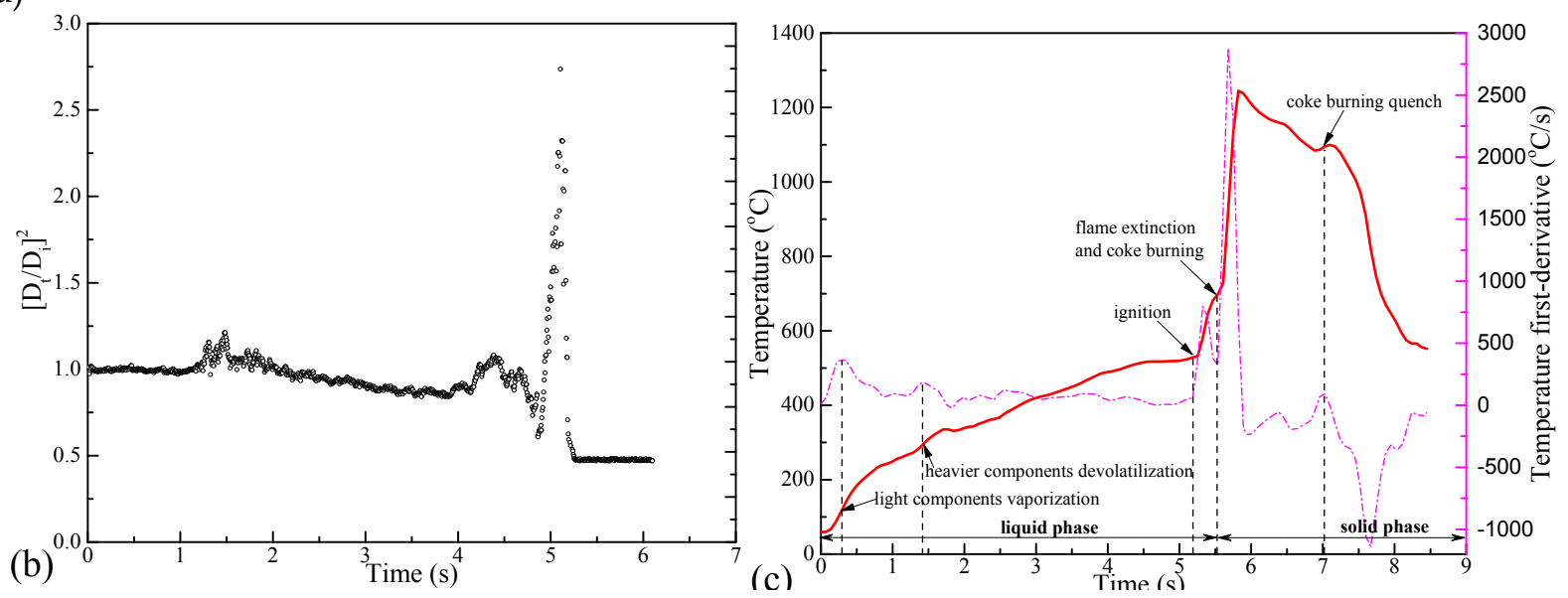

Figure 9 The suspended HFO droplet size and temperature evolution with ignition. (a) Transient images; (b) D square size evolution; (c) suspended droplet temperature history. The initial droplet diameter $\left(D_{i}\right)$ of $820 \mu \mathrm{m}$. $D_{t}$ is the transient droplet diameter.

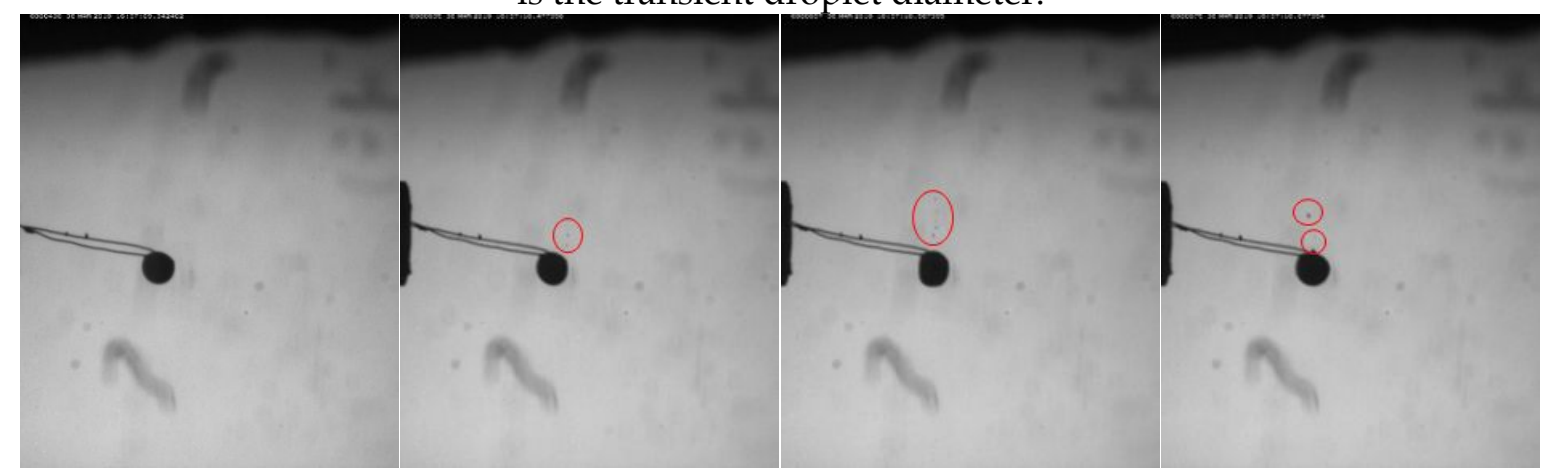




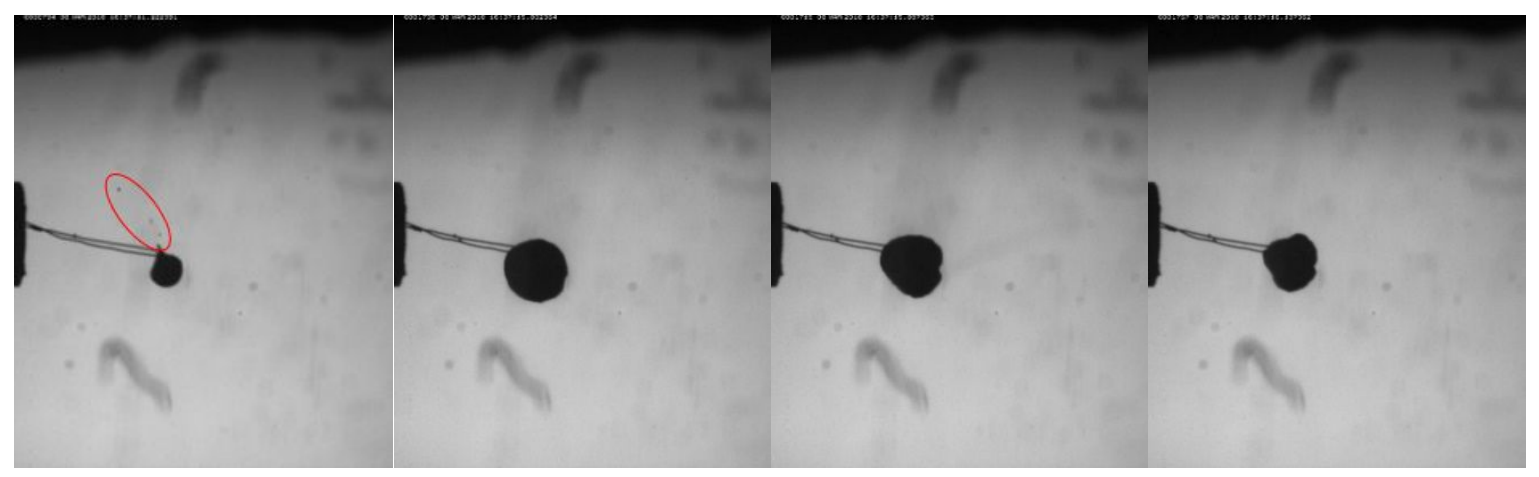

(a)
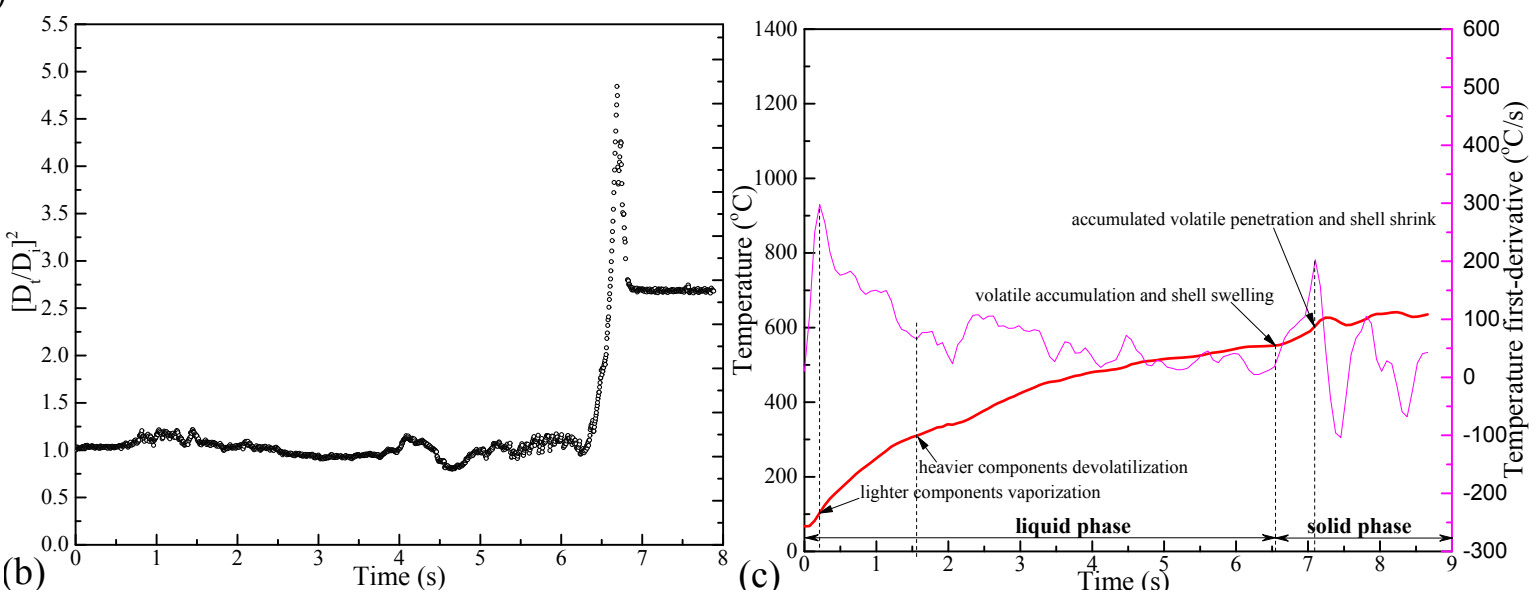

Figure 10 The suspended HFO droplet size and temperature evolution without ignition. (a) Transient images; (b) D square size evolution; (c) suspended droplet temperature history. The initial droplet diameter $\left(\mathrm{D}_{\mathrm{i}}\right)$ of $800 \mu \mathrm{m}$. $\mathrm{D}_{\mathrm{t}}$ is the transient droplet diameter.

3.6 The pathway of different types of cenosphere formation

Based on the elaboration of HFO falling and suspended droplet combustion data, the pathway of different types of cenosphere formation was proposed as shown in Figure 11. When the HFO droplet entered into the combustion area, it would absorb heat from the ambient environment starting at a temperature around $110{ }^{\circ} \mathrm{C}$. Lighter components of HFO droplet first boiled and vaporized. This continuous gaseous diffusion and vaporization caused a swell of HFO droplet, leading to a slight increase of the droplet size (Stage 1). With heat transfer from surface to the interior of the droplet, heavier components of HFO were further devolatilized and cracked at a temperature around $300{ }^{\circ} \mathrm{C}$. The resulting volatiles then released out of the droplet. Meanwhile, this volatile releasing at the surface could cause some small fractions splashing out from the droplet, leading to a decrease of the droplet size (Stage 2). These splashed small fractions would form the type $C$ cenospheres with a perfectly spherical and smooth structure after undergoing combustion process. With volatile diffusion and vaporization, the internal heavier components such as asphaltene in the droplet moved towards the surface and accumulated at the surface, forming a viscous shell. This viscous shell prevented the escape of the volatile components that swelled the droplet between the temperature of $300 \sim 530{ }^{\circ} \mathrm{C}$, leading to another increase of droplet size (Stage 3). The inside accumulated volatiles eventually penetrated through some weak locations of the shell at a temperature around $530{ }^{\circ} \mathrm{C}$, causing the second decrease of the droplet size. If the amount of the 
released volatiles was sufficient within the flammability range, it was ignited by the surrounding hot air flow. This ignition caused a sharp rise in temperature that remarkably enhanced the devolatilization of other components, leading to a quick and significant swell of the HFO droplet (Stage 4). After the depletion of any volatile components, the surface tension caused a fast shrink of the shell at a temperature around $698^{\circ} \mathrm{C}$. The resulting solid residue burned subsequently until quenching, forming the type A cenosphere (Stage 5). If the droplet was not ignited, additional volatile components could also vaporize and accumulate due to an increase of the droplet interior temperature caused by continuous heat transfer from the surrounding atmosphere. However, the droplet swelling was much milder due to much slower droplet interior temperature rise compared to the ignition case. Finally, the accumulated volatile inside the shell released out from some weak positions at a temperature around $600^{\circ} \mathrm{C}$, forming the type B (globule) cenosphere (Stage $4^{\prime}$ ).

The pathway of the factors of temperature, air co-flow rate and asphaltene affecting cenosphere size presented in Figure 7 was also concluded as follow:

With the increase of temperature, the heat transfer from ambient to surface, and interior of the droplet was enhanced. Also, the subsequent vaporization, devolatilization, and diffusion were accelerated. The droplet was easier to be ignited, forming an earlier and more intensive diffusion flame. This diffusion flame could shorten the droplet shell swelling time and enhance the shell shrink, which decreased the cenosphere size.

With the increase of the air co-flow rate, the air surrounding the droplet became sufficient, causing an earlier and more intensive diffusion flame. This intensified diffusion flame, like above, could also shorten the droplet shell swelling time and enhance the shell shrink that consequently resulted in the smaller cenosphere size. Besides, the residence time of droplets inside the furnace varied as the air co-flow rate changed. The droplet residence time inside the drop tube furnace depends on the gravity, the initial droplet velocity, and air drag force around the droplet. To simplify the calculation of the residence time, here the air drag force of the droplet was supposed to be equal to its gravity due to the very small diameter of the droplet. Thus, the droplet was considered to move with a constant velocity. Droplet velocity near the nozzle of the generator was computed as $2.2 \mathrm{~m} / \mathrm{s}$ from images of the high-speed camera by Equation (2). At the temperature of $800{ }^{\circ} \mathrm{C}$, the co-flow air velocity based on the mass flux was calculated as $0.14,0.23,0.42,0.51,0.60$, $0.70 \mathrm{~m} / \mathrm{s}$ according to the air co-flow rates of 30,50, 90, 110, 130 and 150, respectively. Thus, the residence time was separately computed as $641,617,572,554,536,517 \mathrm{~ms}$ according to the above air co-flow rates. It indicates that an increase of air co-flow shorten the residence time of reaction, subsequently decreasing shell swelling time, leading to cenospheres size decreasing. 
As mentioned above, the viscous shell was formed by asphaltene in the droplet moving towards the surface and accumulating at the surface. This viscous shell formation prevented the escape of the volatile components. With the increase of asphaltene content, the viscous shell would be formed earlier, and the shell also became thicker and stronger. Thus, the generated volatiles were more difficult to penetrate through weak locations of the shell, and the shell swelling time was extended which increased the cenosphere size.

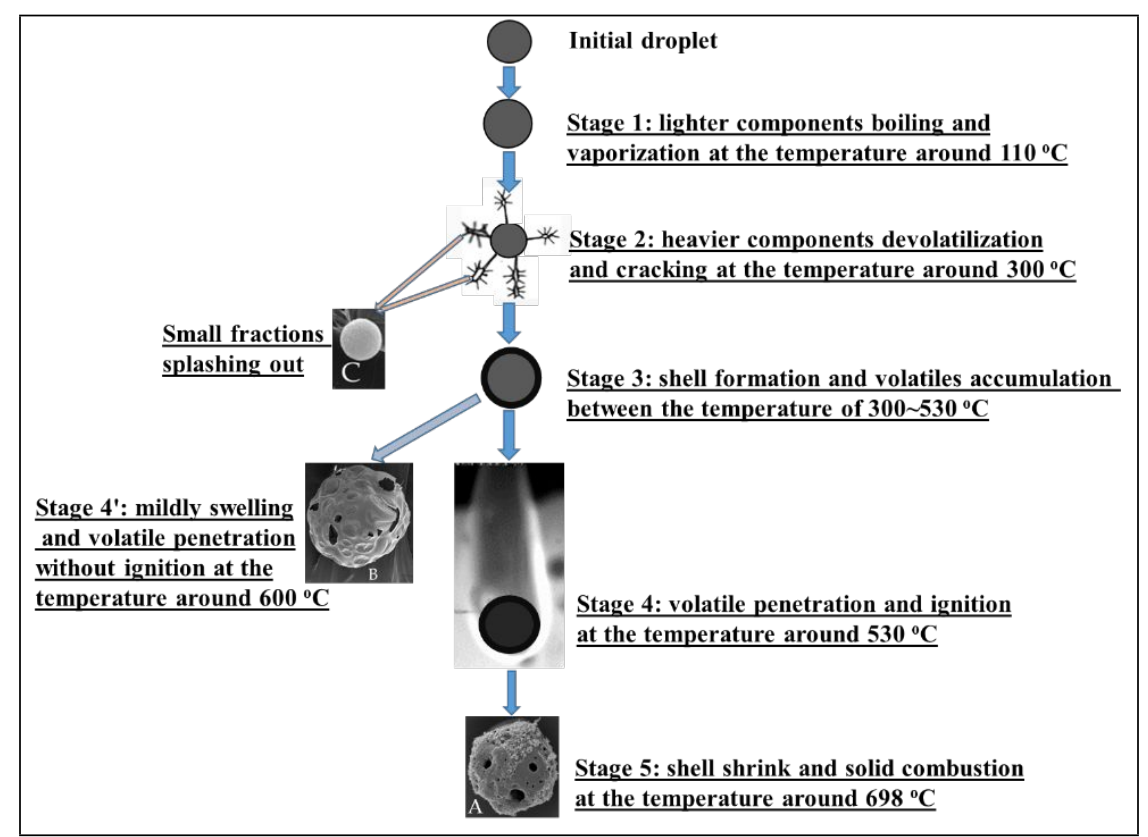

Figure 11 The general pathway of different types of cenosphere formation

\section{Conclusions}

In the current study, we developed a monodisperse droplet generator to uniformly produce single droplets whose size and space were determined by a high-speed camera. The droplet size ranges from 390 to $698 \mu \mathrm{m}$, and the droplet spacing distance is larger than 190 times of average initial droplet diameter that could be sufficient to avoid interference from the droplet-droplet interaction. We then investigated the impacts of the wide range of operating parameters (initial HFO droplet size, temperature, air co-flow rate) and asphaltene content on cenosphere formation in a drop tube furnace which of the topic is not found to be reported in the existing literature. Excluding two familiar types of cenosphere, i.e., larger hollow globules and medium hollow and porous cenosphere, we found a fine cenosphere with a perfectly spherical and smooth structure in the collected cenospheres. The mean diameter of cenospheres ranged from 225 to $300 \mu \mathrm{m}$, nearly half of HFO initial droplet size. These reaction parameters had a linear effect on cenosphere size. Its mean diameter increased with an increase in both initial droplet size and asphaltene content, while decreased with an increase in both temperature and air co-flow rate. Also, they significantly influenced the evolution of the surface elemental composition of cenospheres. The surface contents of $\mathrm{C}, \mathrm{O}$ and $\mathrm{S}$ ranged from 80 to $85 \mathrm{wt} \%, 5$ to $13 \mathrm{wt} \%$, and 4 to $8 \mathrm{wt} \%$, respectively. All parameters 
show a linear effect on the surface contents of $\mathrm{C}, \mathrm{O}$ and $\mathrm{S}$ excluding air co-flow rate. The increase of initial droplet size and asphaltene content linearly enlarged $\mathrm{C}$ content and deduced $\mathrm{O}$ content at the surface of cenospheres, while that of temperature caused a reverse effect on $\mathrm{C}$ and $\mathrm{O}$ content. The increase of temperature enhanced droplet combustion while that of initial droplet size and asphaltene content inhibited droplet combustion. The non-linear effect of air co-flow rate indicates that it has an optimum rate for falling droplet combustion, as $90 \mathrm{slpm}$ based on the current experimental setup. With the aid of the suspended droplet technique, we elaborated the detailed droplet combustion behavior and proposed a formation pathway of different types of cenosphere during HFO droplet combustion. The thermal pathway (time-temperature history) of the droplet corresponding to the different stages of the cenosphere formation was quantitatively defined. The fine cenospheres (type C) were yielded from small fractions splashing out from the droplets starting at a temperature around $300{ }^{\circ} \mathrm{C}$. Formation of the porous cenospheres (type A) and the globules (type B) was dependent on droplet ignition at a temperature around $530{ }^{\circ} \mathrm{C}$, namely the porous cenosphere formation was generated with droplet ignition while the globule formation was generated without droplet ignition.

\section{Acknowledgment}

This work was supported by the Saudi Electricity Company (SEC) under the grant number of RGC/3/3466-01-01, in collaboration with the Clean Combustion Research Center (CCRC) at King Abdullah University of Science and Technology (KAUST).

\section{Appendix A. Supplementary data}

Supplementary data of Video 1 and 2 associated with this article can be found, in the online version, at Supplementary data of Video 1 and Supplementary data of Video 2

\section{Reference}

1. Moldenhauer, P.; Rydén, M.; Mattisson, T.; Jamal, A.; Lyngfelt, A., Chemical-looping combustion with heavy liquid fuels in a 10kW pilot plant. Fuel Processing Technology 2017, 156, (Supplement C), 124-137.

2. Pawelec, A.; Chmielewski, A. G.; Licki, J.; Han, B.; Kim, J.; Kunnummal, N.; Fageeha, O. I., Pilot plant for electron beam treatment of flue gases from heavy fuel oil fired boiler. Fuel Processing Technology 2016, 145, 123-129.

3. Zhou, H.; Ren, T.; Huang, Y.; Hu, S.; Cen, K., Low-NOx Modification of a Heavy Fuel Oil Swirl Burner Based on Semi-Industrial Scale Experimental Tests. Energy \& Fuels 2013, 27, (9), 5029-5035.

4. Joint Organisations Data Initiative - Secondary (all data). http://www.jodidb.org/TableViewer/tableView.aspx.

5. Fattouh, B. The Middle East Refining Scene and Oil Product Balances; Oxford Institute for Energy Studies, :

September 2017.

6. Elbaz, A. M.; Gani, A.; Hourani, N.; Emwas, A.-H.; Sarathy, S. M.; Roberts, W. L., TG/DTG, FT-ICR Mass Spectrometry, and NMR Spectroscopy Study of Heavy Fuel Oil. Energy \& Fuels 2015, 29, (12), 7825-7835. 
7. Bartle, K. D.; Jones, J. M.; Lea-Langton, A. R.; Pourkashanian, M.; Ross, A. B.; Thillaimuthu, J. S.; Waller, P. R.; Williams, A., The combustion of droplets of high-asphaltene heavy oils. Fuel 2013, 103, (Supplement C), 835-842.

8. Sippula, O.; Hokkinen, J.; Puustinen, H.; Yli-Pirilä, P.; Jokiniemi, J., Comparison of particle emissions from small heavy fuel oil and wood-fired boilers. Atmospheric Environment 2009, 43, (32), 4855-4864.

9. Wu, D.; Li, Q.; Ding, X.; Sun, J.; Li, D.; Fu, H.; Teich, M.; Ye, X.; Chen, J., Primary Particulate Matter Emitted from Heavy Fuel and Diesel Oil Combustion in a Typical Container Ship: Characteristics and Toxicity. Environmental Science E Technology 2018, 52, (21), 12943-12951.

10. Corbin, J. C.; Mensah, A. A.; Pieber, S. M.; Orasche, J.; Michalke, B.; Zanatta, M.; Czech, H.; Massabò, D.; Buatier de Mongeot, F.; Mennucci, C.; El Haddad, I.; Kumar, N. K.; Stengel, B.; Huang, Y.; Zimmermann, R.; Prévôt, A. S. H.; Gysel, M., Trace Metals in Soot and PM2.5 from Heavy-Fuel-Oil Combustion in a Marine Engine. Environmental Science \& Technology 2018, 52, (11), 6714-6722.

11. Urban, D. L.; Dryer, F. L., New results on coke formation in the combustion of heavy-fuel droplets. Symposium (International) on Combustion 1991, 23, (1), 1437-1443.

12. Wornat, M. J.; Porter, B. G.; Yang, N. Y. C., single Droplet Combustion of Biomass Pyrolysis Oils. Energy E Fuels 1994, 8, (5), 1131-1142.

13. Bomo, N.; Lahaye, J.; Prado, G.; Claus, G., Formation of cenospheres during pyrolysis of residual fuel oils. Symposium (International) on Combustion 1985, 20, (1), 903-911.

14. Wang, C. H.; Liu, X. Q.; Law, C. K., Combustion and microexplosion of freely falling multicomponent droplets. Combustion and Flame 1984, 56, (2), 175-197.

15. Botero, M. L.; Huang, Y.; Zhu, D. L.; Molina, A.; Law, C. K., Synergistic combustion of droplets of ethanol, diesel and biodiesel mixtures. Fuel 2012, 94, 342-347.

16. Elbaz, A. M.; khateeb, A. A.; Roberts, W. L., PM from the combustion of heavy fuel oils. Energy 2018, 152, 455-465.

17. Setyawan, H. Y.; Zhu, M.; Zhang, Z.; Zhang, D., An Experimental Study of Effect of Water on Ignition and Combustion Characteristics of Single Droplets of Glycerol. Energy Procedia 2015, 75, (Supplement C), 578-583.

18. Ikegami, M.; Xu, G.; Ikeda, K.; Honma, S.; Nagaishi, H.; Dietrich, D. L.; Takeshita, Y., Distinctive combustion stages of single heavy oil droplet under microgravity $\mathfrak{r}^{2}$. Fuel 2003, 82, (3), 293-304.

19. Jacques, M. T.; Jordan, J. B.; Williams, A.; Hadley-Coates, L., The combustion of water-in-oil emulsions and the influence of asphaltene content. Symposium (International) on Combustion 1977, 16, (1), 307-319.

20. Villasenor, R.; Garcia, F., An experimental study of the effects of asphaltenes on heavy fuel oil droplet combustion. Fuel 1999, 78, (8), 933-944.

21. Khateeb, A. A.; Elbaz, A. M.; Guida, P.; Roberts, W. L., Influence of Asphaltene Concentration on the Combustion of a Heavy Fuel Oil Droplet. Energy \& Fuels 2018.

22. Clayton, R. M.; Back, L. H., Physical and Chemical Characteristics of Cenospheres From the Combustion of Heavy Fuel Oil. Journal of Engineering for Gas Turbines and Power 1989, 111, (4), 679-684.

23. Allouis, C.; Beretta, F.; D'Alessio, A., Structure of inorganic and carbonaceous particles emitted from heavy oil combustion. Chemosphere 2003, 51, (10), 1091-1096.

24. Williams, A., Fundamentals of oil combustion. Progress in Energy and Combustion Science 1976, 2, (3), $167-179$.

25. Green, G. J.; Takahashi, F.; Walsh, D. E.; Dryer, F. L., Aerodynamic device for generating mono-disperse fuel droplets. Review of Scientific Instruments 1989, 60, (4), 646-652.

26. Northrop, P. S.; Levendis, Y. A.; Gavalas, G. R., Combustion characteristics of carbonaceous residues from heavy oil fired boilers. Energy \& Fuels 1991, 5, (4), 587-594.

27. Kwack, E. Y.; Shakkottai, P.; Massier, P. F.; Back, L. H., Morphology of Globules and Cenospheres in Heavy Fuel Oil Burner Experiments. Journal of Engineering for Gas Turbines and Power 1992, 114, (2), 338-345.

28. Gay, A. J.; Littlejohn, R. F.; van Duin, P. J., Formation of carbonaceous cenospheres during fluidized-bed combustion of bituminous coals. Fuel 1983, 62, (10), 1224-1226.

29. Feldman, N., Control of residual fuel oil particulate emissions by additives. Symposium (International) on Combustion 1982, 19, (1), 1387-1393.

30. Urban, D. L.; Huey, S. P. C.; Dryer, F. L., Evaluation of the coke formation potential of residual fuel oils. Symposium (International) on Combustion 1992, 24, (1), 1357-1364. 
31. Moszkowicz, P.; Witzel, L.; Claus, G., Modelling of very fast pyrolysis of heavy fuel oil droplets. Chemical Engineering Science 1996, 51, (17), 4075-4086.

32. Ancheyta, J.; Centeno, G.; Trejo, F.; Marroquín, G.; García, J. A.; Tenorio, E.; Torres, A., Extraction and Characterization of Asphaltenes from Different Crude Oils and Solvents. Energy E Fuels 2002, 16, (5), 1121-1127. 33. Boytsova, A.; Kondrasheva, N.; Ancheyta, J., Pyrolysis Kinetics of Heavy Oil Asphaltenes under Steam Atmosphere at Different Pressures. Energy \& Fuels 2018, 32, (2), 1132-1138.

34. Riazi, M. R.; Nasimi, N.; Roomi, Y. A., Estimation of Sulfur Content of Petroleum Products and Crude Oils. Industrial E Engineering Chemistry Research 1999, 38, (11), 4507-4512. 